Кулік Т. О.

\title{
МАТЕМАТИЧНЕ МОДЕЛЮВАННЯ ПРОЦЕСУ ДРЕСИРУВАННЯ ВІДНОСНО ТОНКИХ ЛИСТІВ І СМУГ З УРАХУВАННЯМ РЕАЛЬНИХ ТЕМПЕРАТУР РЕАЛІЗАЦІЇ ПРОЦЕСУ
}

Основним завданням розвитку чорної і кольорової металургії в наш час $є$ підвищення якості готової металопродукції, в тому числі і за рахунок підвищення достовірності інформації, що надається математичними моделями, що, в свою чергу, дозволяє точніше прогнозувати основні показники якості продукції, а також ширше застосовувати системи автоматизації.

Слід зазначити, що одними з найважливіших показників якості відносно тонких стрічок, листів і смуг, що піддають дресируванню, $є$ розподілу залишкових напруг і деформацій. Вони в значній мірі визначають техніко-економічні показники процесів подальшого листового штампування. I саме теплі режими реалізації цього процесу дозволяють управляти розподілами залишкових напружень [1-3].

Метою даної статті є підвищення показників якості відносно тонкого металопрокату, що піддається теплому дресируванню, шляхом уточнення і розширення в обсязі наданої інформації результатів математичного моделювання напружено-деформованого стану і температурних режимів процесу.

В основу математичної моделі процесу теплого дресирування була покладена відома методика розрахунку енергосилових параметрів С. М. Трет’якова [4].

При цьому, для врахування впливу температурного чинника при визначенні опору зсуву пластично формозмінюємого металу була використана методика визначення опору конкретного металу або сплаву пластичної деформації в залежить від температури, представлена в роботі [5]. Так, згідно з цією методикою, опір деформації в реальних умовах реалізації деформування визначають як [6]:

$$
\sigma_{\Phi i}=\sigma_{T i} \cdot n_{t i} \cdot n_{u i} \cdot n_{c i}
$$

де $\sigma_{T i}$ - напруги плинності даного металу, що відповідають умовам стандартних випробувань; $n_{t i}, n_{u i}, n_{c i}$ - коефіцієнти, що враховують відміну, відповідно, температури, швидкості деформації, а також схеми напруженого стану від аналогічних показників, що мали місце при стандартних випробуваннях.

Визначення коефіцієнтів $n_{c i}$ i $n_{u i}$, а також аналітичний опис напруг плинності $\sigma_{T i}$ здійснювали відповідно до методики графічно-аналітичним методом, представленої в роботі [7], використовуючи графічні залежності. Приклад таких залежностей представлено на рис. 1.

Що стосується коефіцієнта $n_{t i}$, який власне і відповідає за урахування впливу температури металу в осередку деформації, для його визначення використовували вираз, який було отримано на основі експоненційної залежності виду[8]:

$$
n_{t i}=\exp \left[m_{1}\left(t_{i}-t_{0}\right)\left(\ln \lambda_{i}\right)^{\left(m_{2}+m_{3} \ln \ln \lambda_{i}\right)}\right]
$$

де $t_{i}$ i $t_{0}$ - температура деформації металу, відповідно, в реальних умовах і при стандартних випробуваннях; $\lambda_{i}=h_{0} / h_{i}=1 /\left(1-\varepsilon_{i}\right)$ - показник витяжки; $m_{1}, m_{2}, m_{3}$ - коефіцієнти, що характеризують інтенсивність зміни механічних властивостей даного металу при зміні температурних умов деформування. 

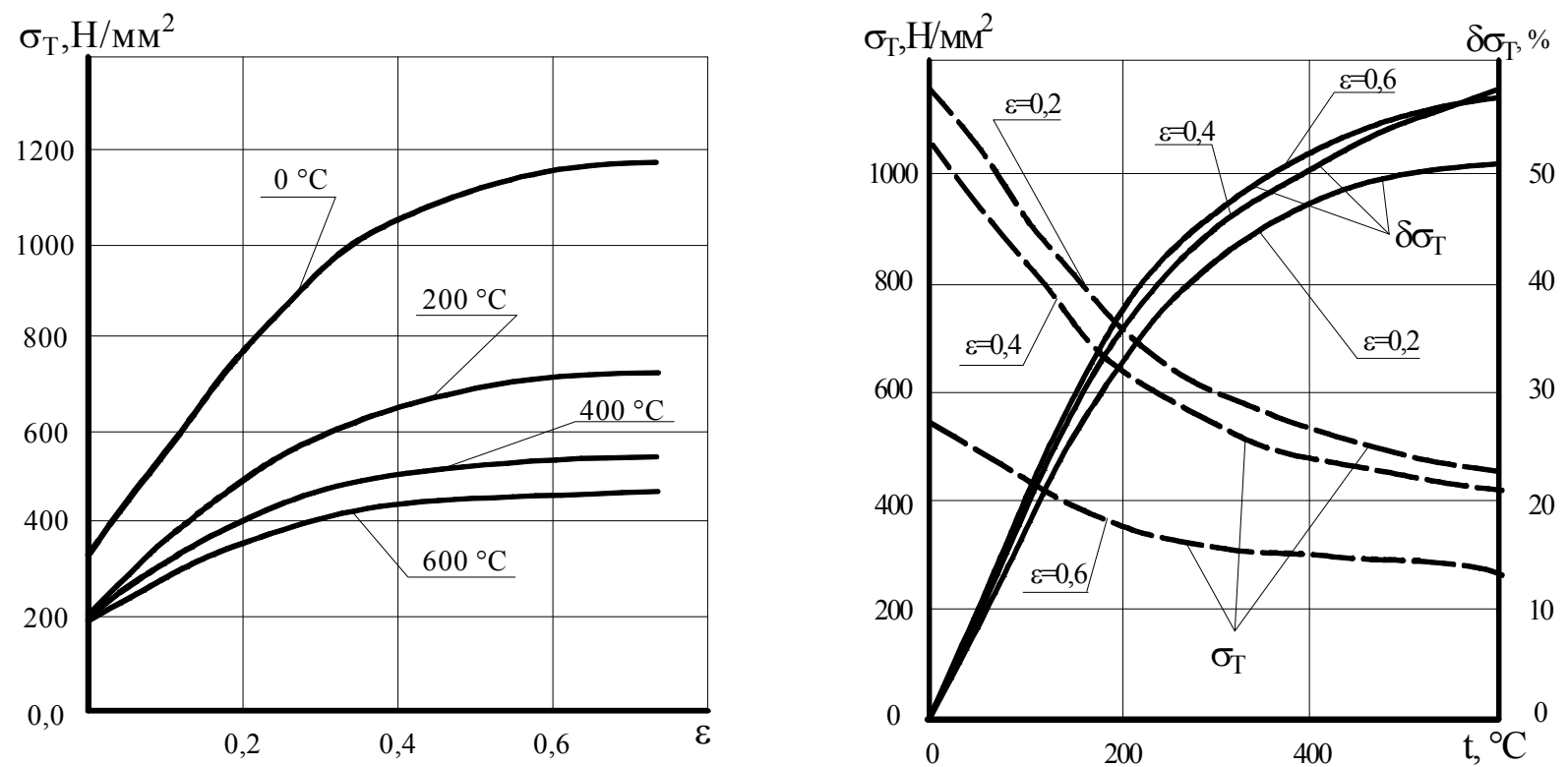

Рис. 1. Експериментальні залежності межі плинності сталі $12 \mathrm{X} 18 \mathrm{H} 9$ в залежності від ступеня і температури деформації [6], використовувані для графічно-аналітичного визначення термомеханічного коефіцієнта $n_{t i}$

Після подвійного логарифмування лівої і правої частин залежність (2) може бути представлена як:

$$
\ln \left(-\ln n_{t i}\right)=\ln \left[-m_{1}\left(t_{i}-t_{0}\right)\right]+m_{2} \ln \ln \lambda_{i}+m_{3}\left(\ln \ln \lambda_{i}\right)^{2}
$$

що за своєю суттю є квадратне рівняння виду:

$$
y_{i}=z_{0}+z_{1} \ln \ln \lambda_{i}+z_{2}\left(\ln \ln \lambda_{i}\right)^{2}
$$

де $y_{i}=\ln \left(-\ln \left(\sigma_{\Phi i} /\left(\sigma_{T i} n_{u i} n_{c i}\right)\right)\right), \quad z_{0}=\ln \left[-m_{1}\left(t_{i}-t_{0}\right)\right], \quad z_{1}=m_{2}, \quad z_{2}=m_{3}$ - допоміжні змінні, використовувані для спрощення форми запису.

Для безпосереднього визначення коефіцієнтів регресії $z_{0}, z_{1}, z_{2}$ були використані емпіричні залежності опору деформації металу при різних температурних, швидкісних і деформаційних умовах реалізації (див. рис. 1). Отриману в результаті систему трьох рівнянь з трьома невідомими вирішували як:

$$
z_{0}=D z_{0} / D ; \quad z_{1}=D z_{1} / D ; \quad z_{2}=D z_{2} / D
$$

де $D, D z_{0}, D z_{1}, D z_{2}$ - визначники третього порядку, відповідні:

$$
\begin{gathered}
D=\left|\begin{array}{rrr}
1 & \ln \ln \left(\lambda_{1}\right) & \left(\ln \ln \left(\lambda_{1}\right)\right)^{2} \\
1 & \ln \ln \left(\lambda_{2}\right) & \left(\ln \ln \left(\lambda_{2}\right)\right)^{2} \\
1 & \ln \ln \left(\lambda_{3}\right) & \left(\ln \ln \left(\lambda_{3}\right)\right)^{2}
\end{array}\right| ; D z_{0}=\left|\begin{array}{lll}
y_{1} & \ln \ln \left(\lambda_{1}\right) & \left(\ln \ln \left(\lambda_{1}\right)\right)^{2} \\
y_{2} & \ln \ln \left(\lambda_{2}\right) & \left(\ln \ln \left(\lambda_{2}\right)\right)^{2} \\
y_{3} & \ln \ln \left(\lambda_{3}\right) & \left(\ln \ln \left(\lambda_{3}\right)\right)^{2}
\end{array}\right| ; \\
D z_{1}=\left|\begin{array}{ccc}
1 & y_{1} & \left(\ln \ln \left(\lambda_{1}\right)\right)^{2} \\
1 & y_{2} & \left(\ln \ln \left(\lambda_{2}\right)\right)^{2} \\
1 & y_{3} & \left(\ln \ln \left(\lambda_{3}\right)\right)^{2}
\end{array}\right| ; D z_{2}=\left|\begin{array}{ccc}
1 & \ln \ln \left(\lambda_{1}\right) & y_{1} \\
1 & \ln \ln \left(\lambda_{2}\right) & y_{2} \\
1 & \ln \ln \left(\lambda_{3}\right) & y_{3}
\end{array}\right| .
\end{gathered}
$$


Отримані в результаті чисельні значення коефіцієнтів регресії дозволили розрахувати коефіцієнти $m_{1}=-\frac{\exp \left(z_{0}\right)}{t_{i}-t_{0}} ; \quad m_{2}=z_{1} ; \quad m_{3}=z_{2}$.

Оскільки коефіцієнти $m_{1}, m_{2}, m_{3}$, в свою чергу, є функціями температури, виникає необхідність в аналітичному описі $m_{l}(t), m_{2}(t), m_{3}(t)$. При цьому залежність $m_{j}(t)$ була прийнята у вигляді поліномів другого ступеня виду:

$$
\left.\begin{array}{l}
m_{1}=b_{0}+b_{1} t_{i}+b_{2} t_{i}^{2} \\
m_{2}=c_{0}+c_{1} t_{i}+c_{2} t_{i}^{2} \\
m_{3}=d_{0}+d_{1} t_{i}+d_{2} t_{i}^{2}
\end{array}\right\}
$$

де безпосереднє визначення коефіцієнтів регресії здійснювали, наразі, також розв'язанням системи трьох лінійних рівнянь з трьома невідомими.

Значення вказаних коефіцієнтів для сталі 12Х18Н9, представлені в табл. 1.

Розрахункові значення коефіцієнтів регресії рівнянь (6)

Таблиця 1

\begin{tabular}{|c|c|c|c|c|c|c|c|c|c|}
\hline \multirow{2}{*}{ Матеріал } & \multicolumn{8}{|c|}{ Розрахункові значення коефіцієнтів регресії } \\
\cline { 2 - 10 } & $b_{0}$ & $b_{1}$ & $b_{2}$ & $c_{0}$ & $c_{1}$ & $c_{2}$ & $d_{0}$ & $d_{1}$ & $d_{2}$ \\
\hline Сталь 12Х18H9 & $2 \cdot 10^{-3}$ & $-1 \cdot 10^{-5}$ & $1 \cdot 10^{-8}$ & $-6,661$ & $-0,0257$ & $-2,6 \cdot 10^{-5}$ & $-1,947$ & 0,0075 & $-8 \cdot 10^{-6}$ \\
\hline
\end{tabular}

Аналіз отриманих в цьому випадку результатів показав, що збільшення температури пропорційне зменшенню термомеханічного коефіцієнту $n_{t j}$ рівняння (1). Представлені розподіли напружень плинності в залежності від ступеня та температури деформації, що отримані з урахуванням більш коректного визначення термомеханічних коефіцієнтів (рис. 2) показали їх якісну відповідність дослідним даним. Отже, їх було використано при подальшому розрахунку процесу дресирування.

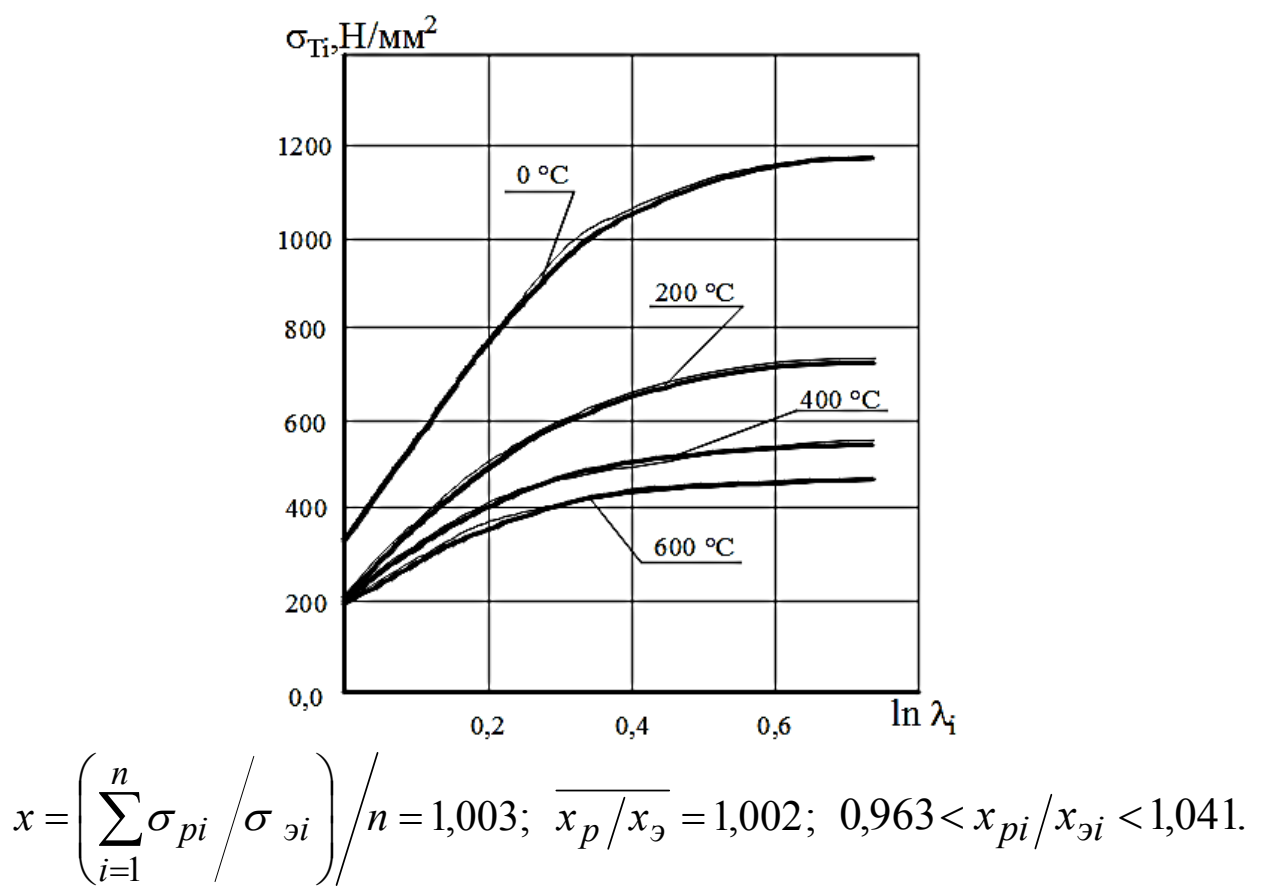

Рис. 2. Експериментальні [6]

і розрахункові розподілу напружень плинності в залежності від ступеня і температури деформації для сталі 12X18H9 
Стосовно до матеріалів, що пластично зміцнюються, в основу методики розрахунку їх залишкових напружень було покладено статечний аналітичний опис функціонального зв'язку напруг і деформацій, яке з урахуванням термомеханічного коефіцієнта $n_{t j}$ дозволило визначити результуючі розподіли деформацій, напружень, температур і залишкових напруг при теплому дресируванні. Для цього використовували методику, що представлена в роботах $[4,9]$.

В основу методики покладено адаптований статечний вираз, аналітична форма запису якого має вигляд:

$$
\sigma_{j}^{*}=C^{*} \cdot \varepsilon_{j}^{n^{*}}
$$

де $C^{*}, n^{*}$ - коефіцієнт регресії і статечний показник, що визначають напруги $\sigma_{j}^{*}$ не тільки $з$ урахуванням ступеня деформації $\varepsilon_{j}$, а й $з$ урахуванням температури $t_{j}$ металу в даній матеріальній точці.

3 урахуванням логарифмування лівих і правих частин, а також з урахуванням співвідношення $\sigma_{j}^{*}=\sigma_{j} \cdot n_{t j}$, рівняння (7) зводиться до вигляду:

$$
\ln \sigma_{j}+\ln n_{t j}=\ln C^{*}+n * \ln \varepsilon_{j}
$$

звідки, з урахуванням відомих, принаймні, двох ( $j=1 \mathrm{i} j=2)$ значень ступеня деформації $\left.\varepsilon_{j}\right|_{j=1},\left.\quad \varepsilon_{j}\right|_{j=2}$, напруг $\left.\sigma_{j}\right|_{j=1},\left.\sigma_{j}\right|_{j=2}$, температури $\left.t_{j}\right|_{j=1},\left.t_{j}\right|_{j=2}$ і відповідних ій термомеханічних коефіцієнтів $\left.n_{t j}\right|_{j=1},\left.n_{t j}\right|_{j=2}$ шляхом розв'язання системи двох рівнянь 3 двома невідомими можуть бути визначені значення коефіцієнтів регресії $C^{*}$ і статистичного показника $n *$. Подальший же розрахунок розподілів напружень і деформацій при теплому дресируванні, а також аналогічний розрахунок розподілів залишкових напружень можуть бути зроблені в повній відповідності з методикою роботи $[4,9]$.

Наявність функціонального зв'язку $n^{*}=f\left(n_{t j}\right)$, а також вплив термомеханічного коефіцієнту $n_{t j}$ на характер розподілів за товщиною металу відносних напруг і деформацій проілюстровано рис. 3 .

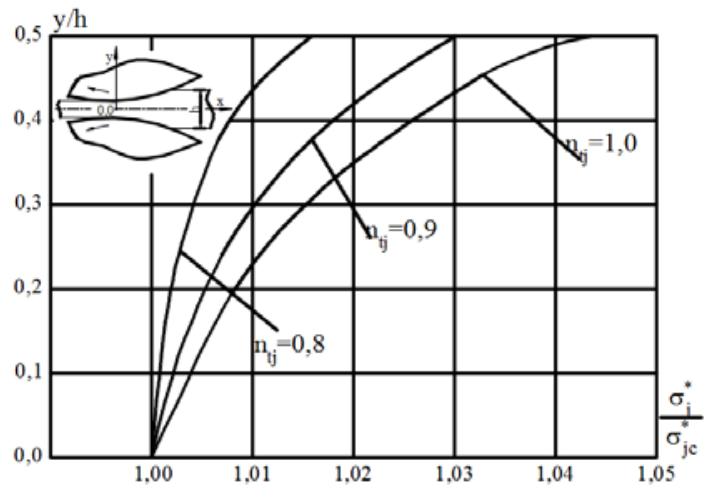

a)

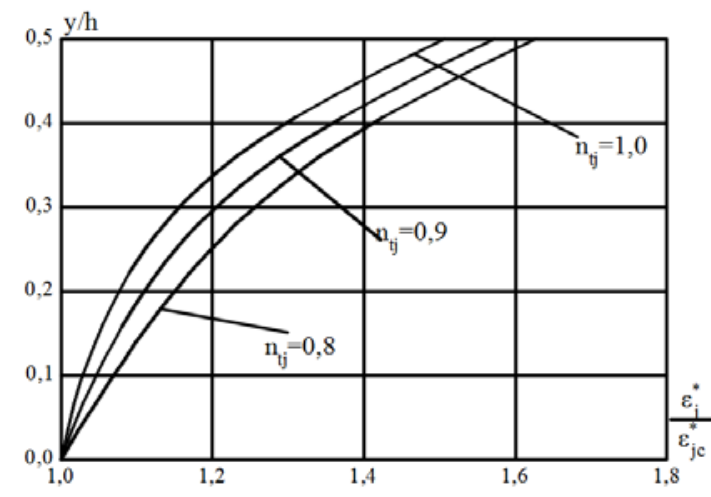

б)

Рис. 3. Розрахункові розподіли відносних напруг $\sigma_{j}^{*}$ (а) і ступеня деформації $\varepsilon_{j}^{*}$ (б) для різних за рівнем ліній струму до аналогічних показників $\sigma_{j c}^{*}, \varepsilon_{j c}^{*}$ для лінії струму по осі смуги $(y / h=0,0)$ в залежності від термомеханічного коефіцієнту $n_{t j}$, що характеризує вплив температурних умов реалізації процесу теплого дресирування (сталь Х18Н10Т, $\varepsilon=0,03, \mu=0,4$ ) 


\section{ВИСНОВКИ}

На основі більш коректного визначення термомеханічних коефіцієнтів, що характеризують вплив температур, уточнена методика розрахунку опору деформації металів і сплавів при реалізації процесу з використанням режимів теплого деформування.

На основі врахування впливу реальних температурних умов уточнена методика моделювання механізму формування залишкових напружень при реалізації процесу теплого дресирування відносно тонких стрічок, листів і смуг. Показано, що підвищення температур призводить до збільшення рівнів залишкових напружень стиску в поверхневих шарах. При цьому максимальна інтенсивність зазначених кількісних змін має місце в разі підведення теплової енергії безпосередньо в осередок деформації через попередньо нагріті робочі валки.

\section{СПИСОК ВИКОРИСТАНОЇ ЛІТЕРАТУРИ}

1. Harshad Bhadeshia. Thermomechanical Treatment of Steels. Microstructure and Properties (Fourth edition). 2017, pp. 271 - 301. DOI: https://doi.org/10.1016/B978-0-08-100270-4.00010-X2

2. Bright G.W., Kennedy J.I., Robinson F., et al. Variability in the mechanical properties and processing conditions of a high strength low alloy steel. Procedia Engineering. 2011, 10, pp. 106-111. DOI: https://doi.org/10.1016/j.proeng.2011.04.020

3. Бергеман Г.В. Способы повышения механических свойств фасонных профилей из углеродистых сталей обыкновенного качества. Пластическая деформация металлов: коллективная монография. Днепропетровск: Акцент ПП. 2014. С. 56-65. ISBN 978-617-7109-18-0

4. Третьяков А.В., Третьяков Е.М., Мигачева Г.Н. Дрессировка и качество тонкого листа. Москва: Металлургия. 1977. $232 \mathrm{c.}$ $1978.368 \mathrm{c}$.

5. Смирнов-Аляев Г.А. Сопротивление материалов пластическому деформированию. Москва: Машгиз.

6. Полухин П.И., Гун Г.Я., Галкин А.М. Сопротивление пластической деформации металлов и сплавов: Справочник. Москва: Металлургия. 1983. 352 с.

7. Потапкин В.Ф., Сатонин А.В., Доброносов Ю.К. Математическая модель физико-механических свойств и запаса пластичности меди и медно-цинковых сплавов при их холодной прокатке. Изв. вузов. Черная металлургия. 1986. 7. С. 58-61.

8. Доброносов Ю.К., Кулик Т.А., Кулик А.Н. Особенности учета реальных температурных условий процесса пластического формоизменения металла при реализации процессов обработки давлением в диапазоне температур теплой деформации. Удосконалення процесів і обладнання обробки тиском в металургії і машинобудуванні: Тематич. зб. наук. пр. Краматорськ. 2000. С. 599-601.

9. Кулик Т.А., Кулик Н.А. Совершенствование качества дрессировки в режиме теплого деформирования путем моделирования механизмов формирования остаточных напряжений. Научный вестник ДГМА. 2017. 2 (23Е). С. 9-13.

\section{REFERENCES}

1. Harshad Bhadeshia. Thermomechanical Treatment of Steels. Microstructure and Properties (Fourth edition). 2017, pp. 271 - 301. DOI: https://doi.org/10.1016/B978-0-08-100270-4.00010-X2

2. Bright G.W., Kennedy J.I., Robinson F., et al. Variability in the mechanical properties and processing conditions of a high strength low alloy steel. Procedia Engineering. 2011, 10, pp. 106-111. DOI: https://doi.org/10.1016/j.proeng.2011.04.020

3. Bergeman G.V. Ways to increase the mechanical properties of shaped profiles of carbon steel of ordinary quality. Plastic deformation of metals: a collective monograph. Dnepropetrovsk: Accent PP. 2014, pp. 56-65. ISBN 978-617-7109-18-0. (in Russian).

4. Tretyakov A.V., Tretyakov E.M., Migacheva G.N. Training and quality of a thin sheet. Moscow: Metallurgy, 1977, 232 p. (in Russian).

5. Smirnov-Alyaev G.A. Resistance of materials to plastic deformation. Moscow: Mashgiz. 1978, 368 p. (in Russian).

6. Polukhin P.I., Gun G. Ya., Galkin A.M. Resistance to plastic deformation of metals and alloys. Handbook. Moscow: Metallurgy. 1983, 352 p. (in Russian).

7. Potapkin V. F., Satonin A. V., Dobronosov Yu. K. A mathematical model of physicomechanical properties and ductility margin of copper and copper-zinc alloys during their cold rolling. Izvestiya. Ferrous Metallurgy. 1986, 7 , pp. 58-61. (in Russian).

8. Dobronosov Yu. K., Kulik T.A., Kulik A.N. Features of taking into account the real temperature conditions of the process of plastic metal forming during the implementation of pressure processes in the temperature range of warm deformation. Improvement of processes and equipment of pressure treatment in metallurgy and mechanical engineering. Kramatorsk: DSEA. 2000, pp. 599-601. (in Russian).

9. Kulik T.A., Kulik N.A. Improving the quality of training in the warm deformation mode by modeling the mechanisms of formation of residual stresses. Scientific Herald of the DSEA. 2017, 2 (23E), pp. 9-13. (in Russian).

Кулік Т. О. - канд. техн. наук, ст. викл. кафедри ОПМ ДДМА.

ДДМА - Донбаська державна машинобудівна академія, м. Краматорськ.

E-mail: okmm@dgma.donetsk.ua 